\title{
G-protein-coupled receptor 30 mediates the effects of estrogen on endothelial cell tube formation in vitro
}

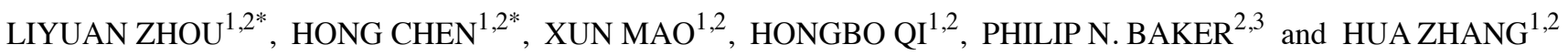 \\ ${ }^{1}$ Department of Obstetrics and Gynaecology, The First Affiliated Hospital of Chongqing Medical University; \\ ${ }^{2}$ Canada-China-New Zealand Joint Laboratory of Maternal and Fetal Medicine, Chongqing Medical University, \\ Chongqing 400016, P.R. China; ${ }^{3}$ Liggins Institute, University of Auckland, Auckland 1142, New Zealand
}

Received May 20, 2016; Accepted April 4, 2017

DOI: $10.3892 / \mathrm{ijmm} .2017 .2957$

\begin{abstract}
The placenta is the exchange organ between the mother and the fetus. The inadequate function of this organ is associated with a number of pregnancy disorders. Hypoxia and oxidative stress during placental development may induce endothelial dysfunction, resulting in the reduction in the perfusion of the placenta. During pregnancy, the levels of estrogen are increased. Decreased estrogen levels have been reported in women with preeclampsia. However, whether estrogen is involved in placental angiogenesis remains unclear. In this study, we aimed to investigate the effects of estrogen on endothelial cell tube formation and to elucidate the underlying mechanisms. For this purpose, human umbilical vein endothelial cells (HUVECs) were cultured with 17- $\beta$-estradiol under conditions of hypoxia/ reoxygenation $(\mathrm{H} / \mathrm{R})$. The total pipe length of the tube-like structure on endothelial cells was measured. The expression levels of G-protein-coupled receptor 30 (GPR30) and endothelial nitric oxide synthase (eNOS) and Akt were also measured in the endothelial cells following treatment with 17- $\beta$-estradiol under $\mathrm{H} / \mathrm{R}$ conditions by western blot analysis and immunostaining. We found that the total pipe length of the tube-like structure on endothelial cells was significantly reduced. This reduction was reversed by treatment with $17-\beta$-estradiol. The expression of GPR30 in endothelial cells was significantly increased following treatment with $17-\beta$-estradiol under H/R conditions. Furthermore, the levels of eNOS and Akt in endothelial cells were also significantly increased following treatment with $17-\beta$-estradiol under H/R conditions. The activation of eNOS
\end{abstract}

Correspondence to: Professor Hua Zhang, Department of Obstetrics and Gynaecology, The First Affiliated Hospital of Chongqing Medical University, 1 Youyi Road, Chongqing 400016, P.R. China

E-mail: zh2844@gmail.com

\section{${ }^{*}$ Contributed equally}

Key words: G-protein-coupled receptor 30, estrogen, angiogenesis, hypoxia-reoxygenation was inhibited by wortmannin, an inhibitor of PI3K/Akt. Our data thus demonstrate that estrogen prevents the failure of endothelial cell tube formation induced by H/R. GPR30 plays an important role in these protective effects through the activation of eNOS and Akt in endothelial cells. Our data suggest that increased levels of estrogen are important for placental angiogenesis.

\section{Introduction}

Successful pregnancy requires normal placental function from adequate placentation and placental vascularization. It may increase proportionally to the organ volume to maintain the number of placental vessels throughout the gestation. Therefore, the study of placental vascularization can enhance our understanding of the physiopathological process of increased resistance in umbilical arteries associated with placental insufficiency. Abnormal placentation causes inadequate utero-placental blood flow (1), resulting in a number of pregnancy complications, including preeclampsia, a leading cause of maternal and perinatal mortality and morbidity (2), and intrauterine growth restriction (IUGR) $(3,4)$.

During normal pregnancy, women experience changes in hormone levels. The levels of both estrogen and progesterone are increased during pregnancy. The blocking of estrogen production results in pregnancy loss in animal models, suggesting that estrogen plays a role in the maintenance of healthy pregnancy. It has been suggested that in addition to its anti-inflammatory effect (5), estrogen also stimulates endothelial cell function and angiogenesis, in particular in vessel formation [reviewed in (6)]. There is growing evidence to suggest that lower levels of estrogen and an increase in progesterone are associated with the pathogenesis of preeclampsia (7-9). However, whether estrogen plays an important role in the regulation of vascular growth in the placenta during pregnancy has not yet been fully investigated.

The biological effects of estrogen are usually mediated by estrogen receptors (ERs) $\alpha$ and $\beta(10,11)$. However, previous studies have suggested that mediating the function of estrogen can be achieved not only through ER $\alpha$ and ER $\beta$. G-protein-coupled receptor 30 (GPR30), identified as a novel estrogen receptor in 2005 has been suggested to mediate the 
action of estrogen $(12,13)$. Recently, we also reported that GPR30 is involved in the development of preeclampsia $(14,15)$. GPR30 is a specific receptor for $17 \beta$-estradiol, a form of estrogens (16), and is expressed in endothelial cells. It is a regulator of the inflammatory response in endothelial cells (5).

Abnormal placentation causes placental ischemia and hypoxia, and it is well known that hypoxia/reoxygenation $(\mathrm{H} / \mathrm{R})$ may be a potential mechanism which contributes to the development of preeclampsia (17). Therefore, we undertook this in vitro study to investigate the effects of estrogen on endothelial cell tube formation, as well as the potential mechanisms responsible for these effects.

\section{Materials and methods}

Reagents. 17- $\beta$-estradiol (E2; ab120657), a general ER agonist, and monoclonal anti-GPR30 (ab154069) antibody were purchased from Abcam (Cambridge, MA, USA). The selective GPR30 agonist, G1, the selective GPR30 inhibitor, G15, and the specific PI3K inhibitor, wortmannin, were purchased from Sigma-Aldrich, St. Louis, MO, USA (G6798, G6748 and W1628, respectively). Anti-endothelial nitric oxide synthase (eNOS; Cat. no. 5880), monoclonal anti-phosphorylated (p-)PI3K (p85; Cat. no. 4228), monoclonal anti-p-eNOS Ser $^{1177}$ (Cat. no. 9570) and monoclonal anti-p-Akt (p-Akt Ser ${ }^{473}$; Cat. no. 4060) antibodies were purchased from Cell Signaling Technology Inc. (Danvers, MA, USA).

Cell culture under $H / R$ conditions. Human umbilical vein endothelial cells (HUVECs) were purchased from Biomics Biotechnologies Co., Ltd. (Nantong, China) and cultured in Medium-1640 (Gibco Life Technologies, Beijing, China) with $10 \%$ (v/v) fetal bovine serum (FBS) (Gibco Life Technologies) at $37^{\circ} \mathrm{C}$ in $5 \% \mathrm{CO}_{2}$ in air. The HUVECs were seeded and grown to $80 \%$ confluence under $\mathrm{H} / \mathrm{R}$ conditions, as previously described (18-21). In brief, to decrease the influence of stimulation by serum mitogens, the HUVECs were incubated for $12 \mathrm{~h}$ in low-serum medium which was supplemented with $1 \%$ FBS prior to exposure to H/R. The HUVECs were then incubated in a hypoxic environment $\left(5 \% \mathrm{CO}_{2}, 94 \% \mathrm{~N}_{2}\right.$ and $1 \% \mathrm{O}_{2}$ ) in a tri-gas cell culture incubator (Thermo Fisher Scientific Oxoid, Ltd., Basingstoke, UK) for $4 \mathrm{~h}$, and subsequently moved to a normoxic incubator with $5 \% \mathrm{CO}_{2}$ in air with normal culture medium (10\% FBS) for a further $18 \mathrm{~h}$. The oxygen concentration inside the tri-gas incubator was monitored by an oxygen analyser (Vascular Technology Inc., Nashua, NH, USA).

In some experiments, the HUVECs were individually pre-treated with $17-\beta$-estradiol (E2) $(100 \mathrm{nM})$ or G1 $(1 \mathrm{mM})$ or $\mathrm{G} 15 \mathrm{(} 2 \mathrm{mM})$ for $1 \mathrm{~h}(5,22)$, and then exposed to $4 \mathrm{~h}$ of hypoxia followed by $18 \mathrm{~h}$ of reoxygenation.

Immunofluorescence. The immunofluorescence staining of GPR30 and p-eNOS in the HUVECs was performed as previously described (23). Following treatment, the HUVECs were fixed in $4 \%$ formaldehyde (Aladdin, Shanghai, China) and blocked with $10 \%$ normal goat serum (Sigma-Aldrich), then incubated with anti-GPR30 antibody (1:80 dilution) or anti-p-eNOS Ser ${ }^{177}$ antibody (1:25 dilution). A fluorescein isothiocyanate-conjugated goat anti-rabbit antibody (1:50 dilution; sc-2012; Santa Cruz Biotechnology, Inc., Santa Cruz, CA, USA) was then used. The nuclei were stained with propidium iodide ( $3 \mathrm{mg} / \mathrm{ml}$; Santa Cruz Biotechnology, Inc.). Images were acquired using a confocal microscope (FV10i; Olympus Corp., Tokyo, Japan).

Western blot analysis. The relative activation levels of eNOS and Akt in the HUVECs following treatment were measured by western blot analysis as described $(18,24)$. Briefly, the HUVECs were homogenised in RIPA buffer (50 mM Tris, $150 \mathrm{mM} \mathrm{NaCl}$, $1 \%$ sodium deoxycholate, $0.1 \%$ SDS, $1 \%$ Nonident P40 substitute, protease inhibitor, $1 \mathrm{mM}$ phenylmethanesulfonylfluoride). All the samples $(10 \mu \mathrm{l})$ were loaded on $6-10 \%$ SDS-PAGE gels and electrophoresed then transferred onto nitrocellulose membranes. Non-specific binding was blocked by incubating membranes in 5\% non-fat milk for $1 \mathrm{~h}$ and the membranes were then incubated with monoclonal anti-GPR30 (1:1,000 dilution) or monoclonal anti-p-PI3K (p85) (1:500 dilution) or polyclonal anti-PI3K (p85) (1:500 dilution; sc-292114; Santa Cruz Biotechnology, Inc.) or monoclonal anti-p-Akt (p-Akt Ser ${ }^{473}$ ) (1:1,000 dilution) or polyclonal anti-Akt (1:500 dilution; sc-5298; Santa Cruz Biotechnology, Inc.) or monoclonal anti-p-eNOS (Ser $\left.{ }^{1177}\right)$ (1:1,000 dilution) or monoclonal anti-eNOS (1:1,000 dilution) antibodies. After washing with PBS-T, the membranes were incubated with goat anti-mouse (1:2,000 dilution; ZB-2305; ZSGB-BIO, Beijing, China) or goat anti-rabbit (1:2,000 dilution; ZB-2301; ZSGB-BIO) secondary antibodies for $1 \mathrm{~h}$ at room temperature. After washing with PBS-T, the membranes were then incubated with streptavidin-conjugated horseradish peroxidase $(1: 3,000)$ for $1 \mathrm{~h}$ at room temperature. After washing with (PBS-T), the membranes were incubated with Amersham ${ }^{\mathrm{TM}}$ ECL $^{\mathrm{TM}}$ Prime Western blotting detection reagent. $\beta$-actin (1:500 dilution; A1978; Sigma-Aldrich) was used as a loading control.

In vitro tube formation assay. The in vitro tube formation assay in the HUVECs was performed as previously described $(18,25)$. Matrigel (BD Biosciences, Franklin Lakes, NJ, USA) was thawed at $4^{\circ} \mathrm{C}$ overnight and then diluted with serum-free medium at a ratio of $1: 2$; the mixture was distributed into a 96-well plate $(65 \mu \mathrm{l} /$ well $)$ and incubated at $37^{\circ} \mathrm{C}$ for $2 \mathrm{~h}$. The HUVECs $\left(1.0 \times 10^{4}\right)$, subjected to a variety of pre-treatments, were added to wells in triplicate under $\mathrm{H} / \mathrm{R}$ conditions (hypoxia for $4 \mathrm{~h}$ and reoxygenation for $18 \mathrm{~h}$ ) or culture in normal oxygen for $22 \mathrm{~h}$. Following treatment, the cultures were captured from each well using a microscope (Olympus Corp.) (5 for each, x100 magnification). The total pipe length of the tube-like structure was calculated by using image-Pro Plus software (version 6.0; NIH image). Tracks of HUVECs organised into networks of cellular cords were counted and averaged in 5 randomly selected view fields (x100 magnification). The tube formation indexes were expressed as tube length $(\mathrm{mm}) / \mathrm{mm}^{2}$ area.

Statistical analysis. All the experiments in this study were performed at least 3 times and the data are expressed as the means \pm standard deviation (SD). Statistical analyses were performed using Graph Pad Prism 5.0 (GraphPad Software Inc., La Jolla, CA, USA). Differences between 2 groups were anal- 

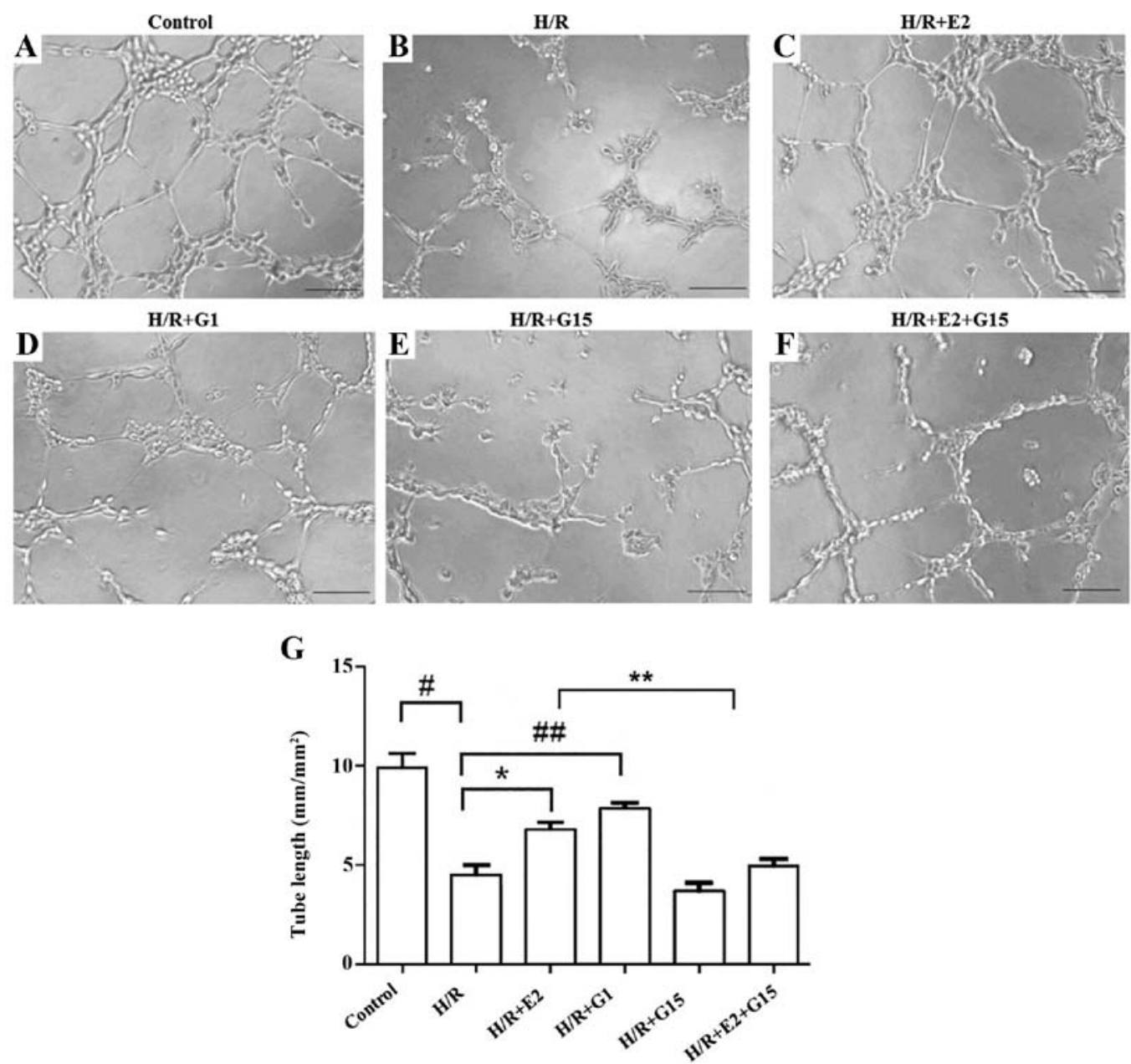

Figure 1. (A-F) Representative images showing endothelial cell tube formation. (A) Endothelial cell tube formation under normoxic conditions; (B) endothelial cell tube formation under hypoxia-reoxygenation $(\mathrm{H} / \mathrm{R})$ conditions; $(\mathrm{C})$ endothelial cell tube formation under $\mathrm{H} / \mathrm{R}$ conditions in the presence of $17-\beta$-estradiol $(\mathrm{E} 2)$; (D) endothelial cell tube formation under H/R in the presence of G1; (E) endothelial cell tube formation under H/R conditions in the presence of G15; (F) endothelial cell tube formation under $\mathrm{H} / \mathrm{R}$ in the presence of $\mathrm{E} 2$ with $\mathrm{G} 15$; and $(\mathrm{G})$ showing the quantification of endothelial cell tube formation. $\left({ }^{\sharp} \mathrm{P}=0.003\right.$, ${ }^{*} \mathrm{P}=0.017$, ${ }^{\#} \mathrm{P}=0.003$, and ${ }^{* *} \mathrm{P}=0.021$ ).

ysed by independent t-test assuming, while differences between multi-groups were analysed by one-way ANOVA. A value of $\mathrm{P}<0.05$ was considered to indicate a statistically significant difference.

\section{Results}

A previous study suggested that estrogen has an effect on endothelial cell angiogenesis (6). In this study, to further investigate the effects of estrogen on endothelial cell tube formation, the total pipe length of the tube-like structure in HUVECs that had been treated with $17-\beta$-estradiol (E2) or the selective GPR30 agonist, G1, was measured after $22 \mathrm{~h}$ of culture under H/R conditions (Fig. 1A-F). The total pipe length of the tube-like structure in the HUVECs that had been cultured under H/R conditions was significantly reduced compared to the HUVECs that were cultured under normoxic control conditions (Fig. 1G; $\mathrm{P}=0.003$ ). This reduction was reversed by pre-treatment with $17-\beta$-estradiol (E2) (Fig. $1 \mathrm{G} ; \mathrm{P}=0.017$ ) or $\mathrm{G} 1$ (Fig. 1G; $\mathrm{P}=0.003$ ). However, the protective effects of $17-\beta$-estradiol (E2) on tube formation were inhibited by G15 (Fig. 1G; $\mathrm{P}=0.021$ ).
In order to investigate whether GPR30, one of the estrogen receptors, is involved in the protective effects of 17- $\beta$-estradiol (E2) on endothelial cell tube formation, GPR30 expression in HUVECs was measured in the presence or absence of $17-\beta$-estradiol (E2) or G1 in culture under $\mathrm{H} / \mathrm{R}$ conditions. The expression of GPR30 was significantly decreased under $\mathrm{H} / \mathrm{R}$ conditions compared with that under normoxic conditions (Fig. 2). However, this reduction of GPR30 expression in the HUVECs induced by H/R conditions was significantly reversed when the cells were pre-treated with $17-\beta$-estradiol (E2) or G1 (Fig. 2). Howeveer, the effects of $17-\beta$-estradiol (E2) and G1 were inhibited by treatment with the specific GPR30 inhibitor, G15 (Fig. 2). The decrease in GPR30 expression in the HUVECs was also confirmed by western blot analysis (Fig. 3; $\mathrm{P}<0.001$ ).

It has previously been suggested that GPR30 activates eNOS. The activation of eNOS is involved in angiogenesis (26-28). In this study, we further investigated whether eNOS is involved in tube formation of endothelial cells in vitro under H/R conditions. Immunofluorescence revealed that the levels of p-eNOS ( $\left.\mathrm{Ser}^{1177}\right)$ in the HUVECs were decreased under $\mathrm{H} / \mathrm{R}$ conditions and following treatment with G15 compared 


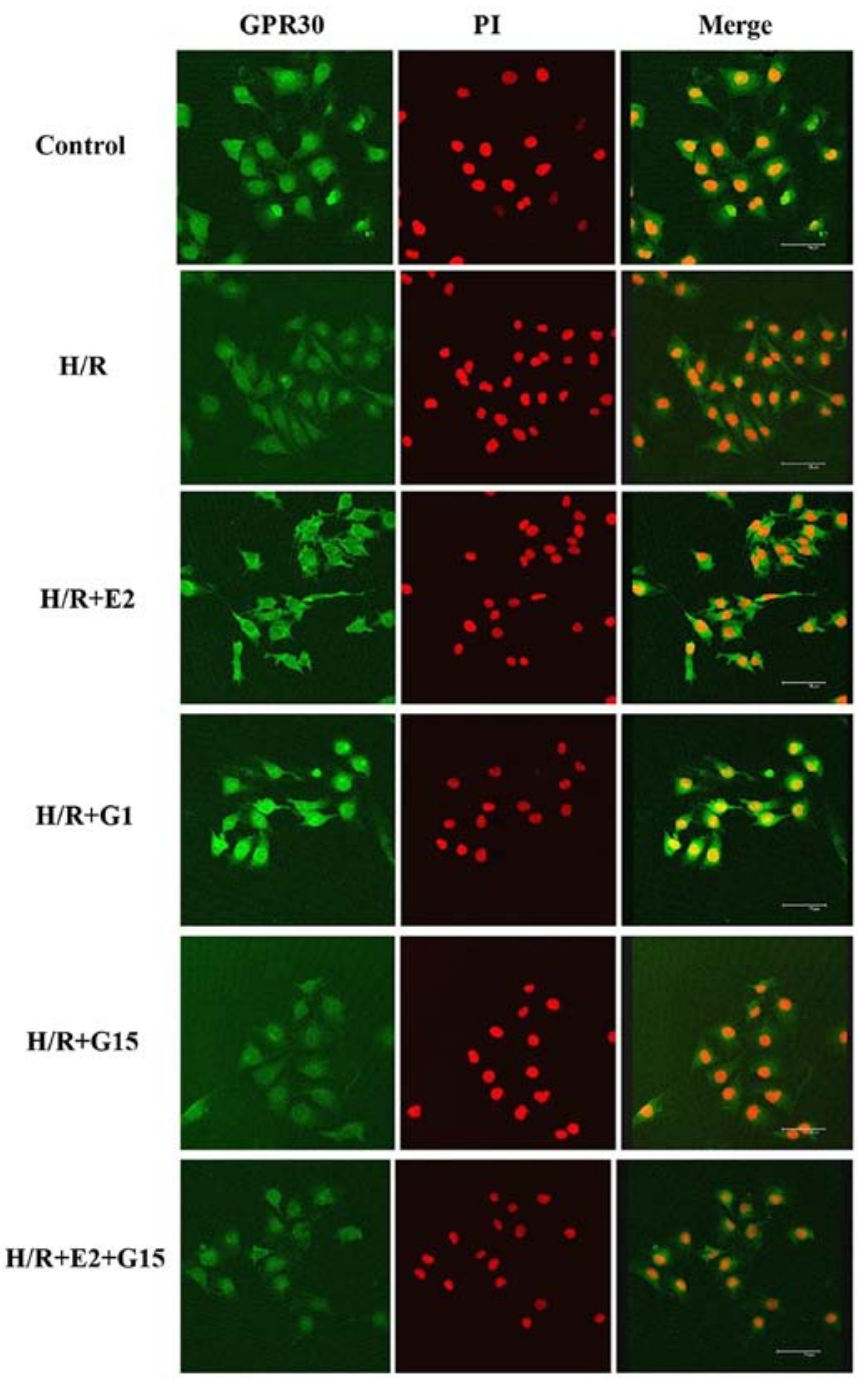

Figure 2. Immunofluorescence images demonstrating the staining of G-protein-coupled receptor 30 (GPR30) in human umbilical vein endothelial cells (scale bar, $75 \mu \mathrm{m}$ ). E2, 17- $\beta$-estradiol; $\mathrm{H} / \mathrm{R}$, hypoxia-reoxygenation.

with the control group (Fig. 4A). The decrease in the expression of $\mathrm{p}$-eNOS at $\mathrm{Ser}^{1177}$ in the HUVECs under H/R conditions was also confirmed by western blot analysis (Fig. 4B; P=0.0132). However, the decrease in p-eNOS expression was reversed by pre-treatment with 17- $\beta$-estradiol (E2) (Fig. 4B; $\mathrm{P}=0.0052$ ) or the selective GPR30 agonist, G1 (Fig. 4B; $\mathrm{P}=0.0123$ ). However, the effects of $17-\beta$-estradiol (E2) were inhibited by treatment with G15 (Fig. 4B; $\mathrm{P}=0.0005$ ).

We further investigated the estrogen-mediated phosphorylation of PI3K (p85) and Akt $\left(\mathrm{Ser}^{473}\right)$ in the HUVECs under $\mathrm{H} / \mathrm{R}$ conditions. The expression ofp-PI3K(p85) and p-Akt $\left(\mathrm{Ser}^{473}\right)$ in the HUVECs was significantly increased by pre-treatment with either G1 (Fig. 5A and B; $\mathrm{P}=0.0001$ and $\mathrm{P}=0.0027$, respectively) or $17-\beta$-estradiol (E2) (Fig. $5 \mathrm{~A}$ and $\mathrm{B} ; \mathrm{P}=0.0001$ ). This effect of $17-\beta$-estradiol (E2) was inhibited by treatment with G15 (Fig. 5A and B; $\mathrm{P}<0.0001$ and $\mathrm{P}=0.0098$ ).

We then investigated whether the PI3K/Akt signalling pathway mediates GPR30-dependent eNOS activation in HUVECs under $H / R$ conditions. The effects of $17-\beta$-estradiol (E2) and G1 on eNOS phosphorylation in
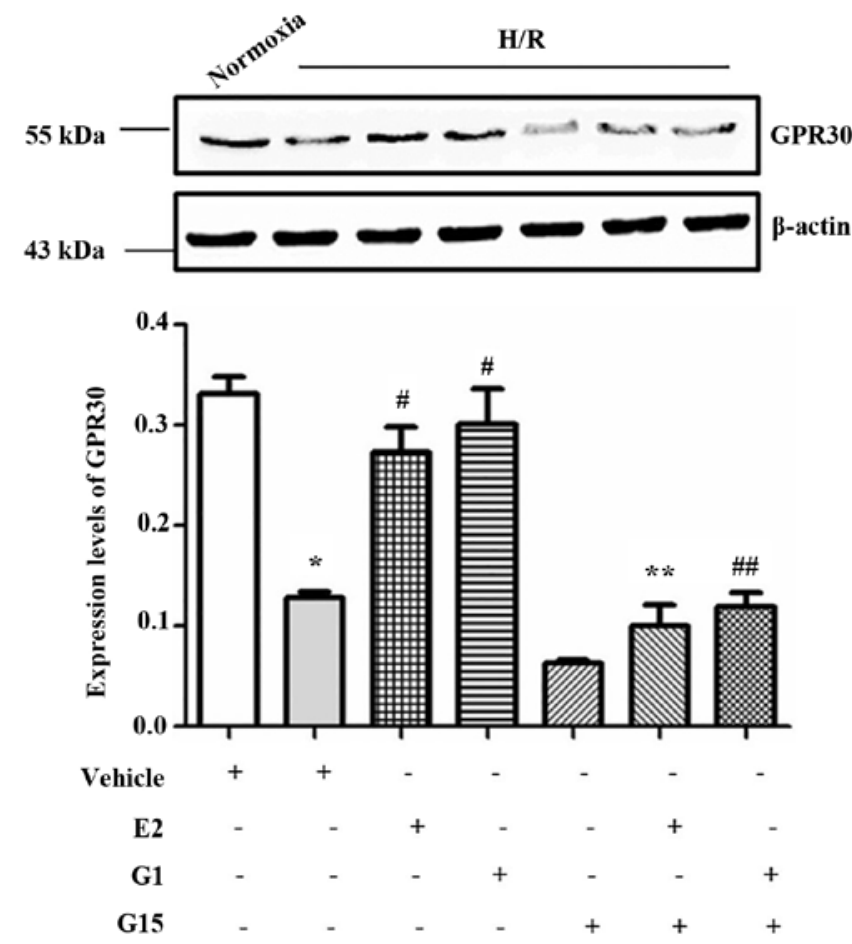

Figure 3. Western blot analysis demonstrating that the levels of G-proteincoupled receptor 30 (GPR30) were decreased under hypoxia-reoxygenation $(\mathrm{H} / \mathrm{R})$ conditions in human umbilical vein endothelial cells (HUVECs) compared to normoxic conditions. The levels of GPR30 were increased in the presence of 17- $\beta$-estradiol (E2) in HUVECs under H/R conditions. Semi-quantitative analysis revealed that when normalised to the levels of $\beta$-actin, the levels of GPR30 were significantly decreased in HUVECs under $\mathrm{H} / \mathrm{R}$ conditions ( $\mathrm{P}<0.001)$; however, these levels were significantly increased in the presence of $\mathrm{E} 2$ or $\mathrm{G} 1{ }^{\#} \mathrm{P}=0.002$, or $\left.{ }^{\#} \mathrm{P}=0.0004\right)$. These effects were inhibited by the addition of $\mathrm{G} 15\left({ }^{* *} \mathrm{P}=0.0004\right.$ or $\left.{ }^{\# \#} \mathrm{P}=0.0002\right)$.

the HUVECs were blocked by the PI3K inhibitor, wortmannin (Wort, $100 \mathrm{nM}$ ) (Fig. 5C; $\mathrm{P}<0.0001$ ).

\section{Discussion}

During human pregnancy, the placenta is supplied with maternal blood via the uterine spiral arteries. The fetus requires an increasing supply of oxygen and nutrients, suggesting that uterine spiral artery remodelling is necessary for a successful pregnancy. However, the failure of spiral artery remodelling impacts the oxygen concentration analogous to hypoxia-reperfusion within the placental environment. A decreased feto-placental perfusion and restricted oxygen delivery causes placental insufficiency, resulting in a number of complications of pregnancy, such as preeclampsia and IUGR. $\mathrm{H} / \mathrm{R}$ is a secondary to intermittent perfusion of the intervillous space and plays an important role in placental development (17). Studies have suggested that H/R causes apoptotic changes in syncytiotrophoblasts, which is another characteristic feature of the preeclamptic placenta $(29,30)$. During normal pregnancy, women experience changes in hormone levels and the levels of both estrogen and progesterone are increased. Lower levels of estrogen have been reported in women with preeclampsia (7-9). However, whether estrogen has an effect on placental vasculature is unknown. 
A
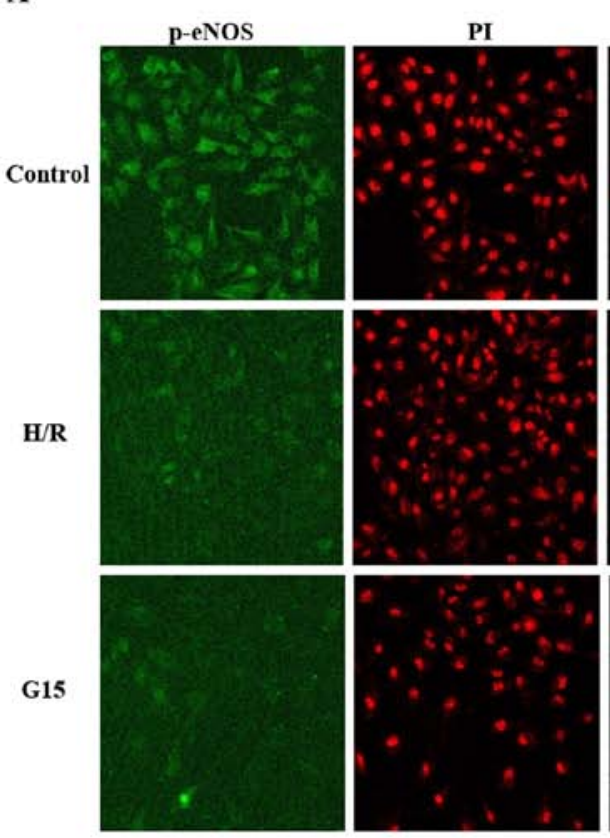

G15

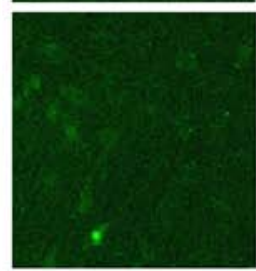

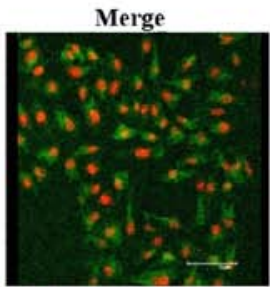
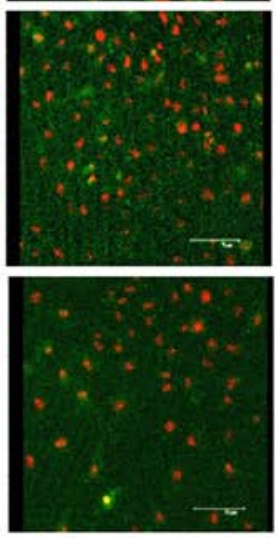

B
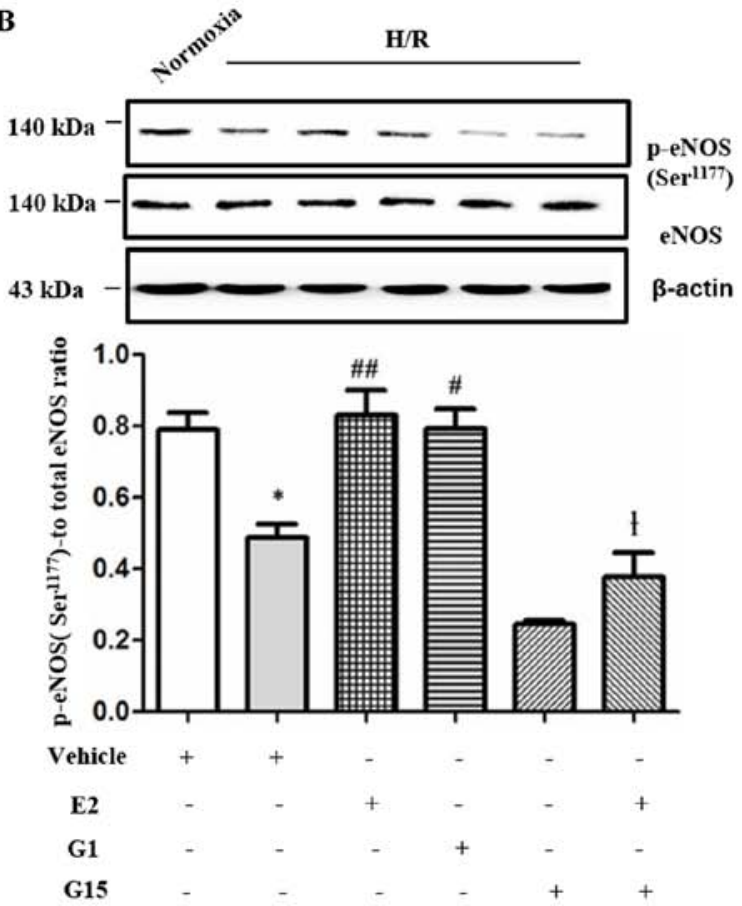

Figure 4. (A) Immunofluorescence images demonstrating the staining of p-eNOS (Ser ${ }^{1177}$ ) in human umbilical vein endothelial cells (HUVECs) (scale bar, $75 \mu$ m). (B) Western blot analysis demonstrating that the levels of p-eNOS ( $\mathrm{Ser}^{1177}$ ) were decreased under hypoxia-reoxygenation (H/R) conditions in HUVECs compared to normoxic conditions. The levels of p-eNOS $\left(\operatorname{Ser}^{1177}\right)$ were increased in the presence of E2 in HUVECs under H/R conditions. Semi-quantitative analysis revealed that when normalised to the levels of $\beta$-actin, the levels of p-eNOS $\left(\mathrm{Ser}^{1177}\right)$ were significantly decreased in $\mathrm{HUVECs}$ under $\mathrm{H} / \mathrm{R}$ conditions $\left({ }^{*} \mathrm{P}=0.132\right)$, but were significantly increased in the presence of $\mathrm{E} 2$ or $\mathrm{G} 1\left({ }^{\# \#} \mathrm{P}=0.0052\right.$, or $\left.{ }^{\#} \mathrm{P}=0.0123\right)$. These effects were inhibited by the addition of $\mathrm{G} 15\left({ }^{* *} \mathrm{P}=0.0005\right)$. eNOS, endothelial nitric oxide synthase; E2, 17- $\beta$-estradiol.
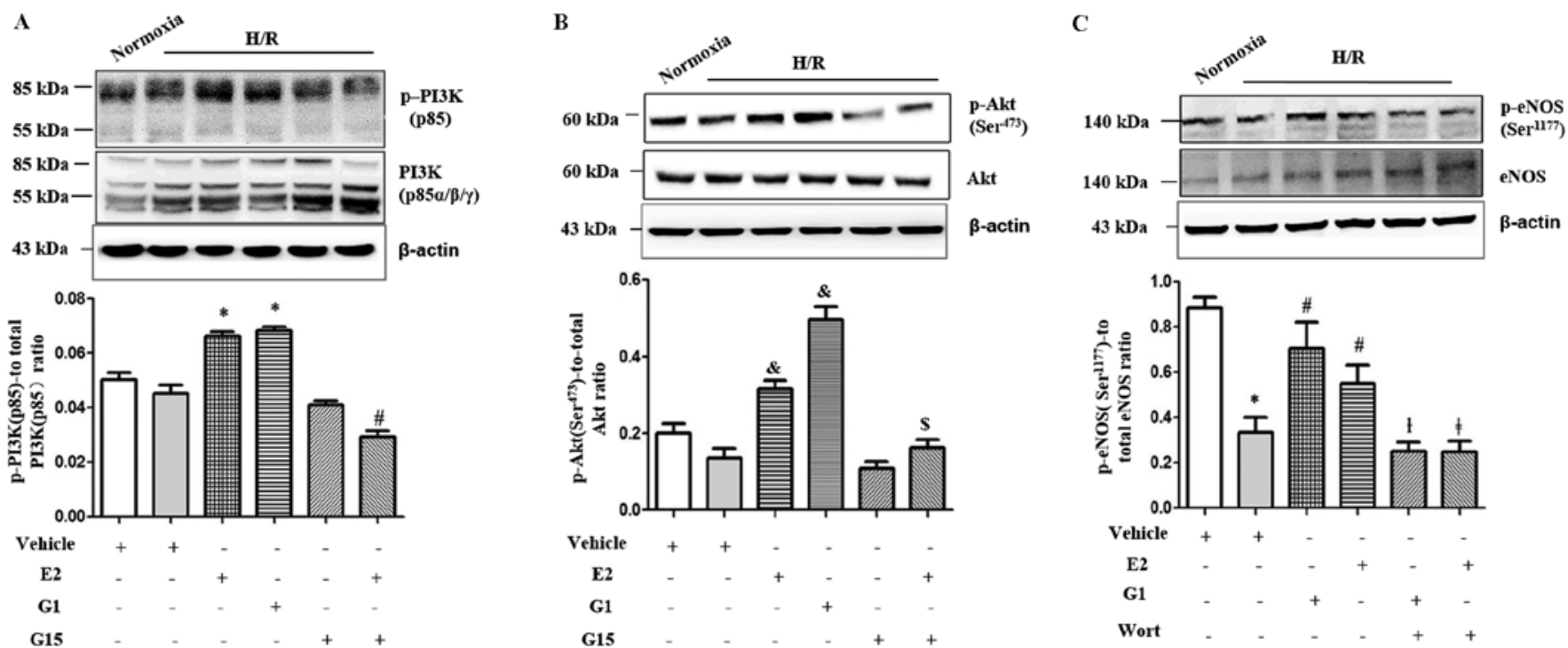

Figure 5. Western blot analysis demonstraing that the levels of (A) p-PI3K (p85) and (B) p-Akt (Ser ${ }^{473}$ ) were significantly increased in the presence of E2 (A and $\mathrm{B},{ }^{*} \mathrm{P}=0.0001$ and ${ }^{\&} \mathrm{P}=0.0001$, respectively) or $\mathrm{G} 1$ (A and $\mathrm{B},{ }^{*} \mathrm{P}=0.0001$ and ${ }^{\&} \mathrm{P}=0.0027$, respectively) in human umbilical vein endothelial cells (HUVECs) under hypoxia-reoxygenation $(\mathrm{H} / \mathrm{R})$ conditions. The effect was blocked by treatment with $\mathrm{G} 15$ (A and $\mathrm{B},{ }^{*} \mathrm{P}<0.0001$ and ${ }^{\$} \mathrm{P}=0.0098$, respectively). Western blot analysis also demonstrated that the levels of $(\mathrm{C}) \mathrm{p}$-eNOS $\left(\mathrm{Ser}^{1777}\right)$ were significantly decreased under H/R conditions in HUVECs compared to normoxic conditions ( $\left.{ }^{*} \mathrm{P}=0.0111\right)$. This decrease was significantly increased in the presence of $\mathrm{E} 2$ or $\mathrm{G} 1$ in $\mathrm{HUVECs}$ under $\mathrm{H} / \mathrm{R}$ conditions $\left({ }^{\sharp} \mathrm{P}<0.0043\right.$ and $\left.\mathrm{P}=0.0104\right)$. This effect was significantly blocked by treatment with wortmannin (Wort, $100 \mathrm{nM})\left({ }^{* *} \mathrm{P}<0.0001,{ }^{\# \#} \mathrm{P}<0.0001\right)$. eNOS, endothelial nitric oxide synthase; E2, $17-\beta$-estradiol.

Placental vasculature expands in both maternal and fetal placental tissue during pregnancy (31). Endothelial cell tube formation assay is a common tool to study angiogenesis. In this in vitro study, we found that the supplementation of $17-\beta$-estradiol (E2), a form of estrogen reversed the failure of endothelial cell tube formation induced by $\mathrm{H} / \mathrm{R}$. Another study demonstrated that estrogen, such as $17-\beta$-estradiol (E2) plays a role in the modulation of endothelial cell function and in 
the promotion of angiogenesis (6). That study also suggested that the effect of 17- $\beta$-estradiol (E2) on angiogenesis may also apply to in vivo (6). A recent study further suggested that $17-\beta$-estradiol (E2) was able to protect cardiomyocytes against H/R injury (32). To understand the specific mechanisms of estrogen by which receptors improve endothelial cell tube formation, in this in vitro study, we found that the expression of GPR30, a novel estrogen receptor was significantly reduced in endothelial cells under $\mathrm{H} / \mathrm{R}$ conditions. However, this decreased expression of GPR30 was reversed by the supplementation of 17- $\beta$-estradiol (E2) or a selective GPR30 agonist (G1) in endothelial cells under H/R conditions. GPR30 is associated with the protective effects of estrogen in breast cancer $(12,13)$. A recent study also suggested that the GPR30 agonist, G1, improves cerebral microvascular function following H/R injury in animal model (33). Taken together, our data suggest that $17-\beta$-estradiol (E2) may have a similar function as the GPR30 agonist, G1. 17- $\beta$-estradiol (E2) is involved in the regulation of endothelial cell tube formation in H/R injury and its protective effects are associated with estrogen receptor, GPR30, in endothelial cells.

Reactive oxygen species (ROS) play an important role in endothelial cell dysfunction (34) and multiple ROS systems are activated during H/R, including NOS (35). A number of studies have suggested that the activation of eNOS is involved in angiogenesis (26,36). Endogenous estrogens mediate protective effects at least partially due to the activation of eNOS and the bioactivity of NO is regulated by GPR30 in the cardiovascular system. In addition, the protective effects of the GPR30 agonist, G1, in endothelial cells following $\mathrm{H} / \mathrm{R}$ injury, at least partially also depends on eNOS (33). In this in vitro study, consistent with other studies, we found that the decreased expression of eNOS induced by $H / R$ was reversed by the addition of $17-\beta$-estradiol (E2) or the GPR30 agonist, G1, in endothelial cell culture.

A previous study suggested that in addition to the association with the expression of eNOS, GPR30 also mediated the activation of Akt in endothelial cells (37) and is involved in cell proliferation (38). In this in vitro study, we also found that the expression of Akt was decreased by $\mathrm{H} / \mathrm{R}$ in endothelial cells; however, this decrease in Akt expression was reversed by supplementation with either 17- $\beta$-estradiol (E2) or the GPR30 agonist, G1. We further found that the activation of eNOS induced by $17-\beta$-estradiol (E2) or the GPR30 agonist, G1, was inhibited by an inhibitor of PI3K/Akt (wortmannin), suggesting the activation of eNOS induced by $17-\beta$-estradiol (E2) is Akt-dependent in endothelial cells under H/R conditions. Taken together our data suggest that both eNOS and PI3K/Akt activation are involved in the prevention of endothelial cell tube formation by $17-\beta$-estradiol (E2), and the PI3K/Akt signalling pathway regulates the activation of eNOS in the prevention of endothelial cell tube formation by $17-\beta$-estradiol (E2).

In conclusion, to the best of our knowledge, in the present in vitro study, we report for the first time that the supplementation of estrogen 17- $\beta$-estradiol (E2) may prevent the failure of endothelial cell tube formation induced by $\mathrm{H} / \mathrm{R}$. The estrogen receptor, GPR30, is at least partially involved in this protective effect through the activation of eNOS and the Akt signalling pathway in endothelial cells. Lower levels of estrogen are reported in complications of pregnancy, such as preeclampsia. Therefore, our data suggest that increased levels of estrogen during normal pregnancy promote placental vasculature development, thus exerting positive effects.

\section{Acknowledgements}

This study was supported by the National Natural Science Foundation of China (nos. 81370732 and 81571453).

\section{References}

1. Khong Y and Brosens I: Defective deep placentation. Best Pract Res Clin Obstet Gynaecol 25: 301-311, 2011.

2. Sibai B, Dekker G and Kupferminc M: Pre-eclampsia. Lancet 365: 785-799, 2005.

3. Roberts JM and Hubel CA: Is oxidative stress the link in the two-stage model of pre-eclampsia? Lancet 354: 788-789, 1999.

4. Hubel CA: Oxidative stress in the pathogenesis of preeclampsia. Proc Soc Exp Biol Med 222: 222-235, 1999.

5. Chakrabarti S and Davidge ST: G-protein coupled receptor 30 (GPR30): A novel regulator of endothelial inflammation. PLoS One 7: e52357, 2012.

6. Rubanyi GM, Johns A and Kauser K: Effect of estrogen on endothelial function and angiogenesis. Vascul Pharmacol 38: 89-98, 2002.

7. Zeisler H, Jirecek S, Hohlagschwandtner M,Knöfler M, Tempfer C and Livingston JC: Concentrations of estrogens in patients with preeclampsia. Wien Klin Wochenschr 114: 458-461, 2002.

8. Tamimi R, Lagiou P, Vatten LJ, Mucci L, Trichopoulos D, Hellerstein S, Ekbom A, Adami HO and Hsieh CC: Pregnancy hormones, pre-eclampsia, and implications for breast cancer risk in the offspring. Cancer Epidemiol Biomarkers Prev 12: 647-650, 2003.

9. Jobe SO, Tyler CT and Magness RR: Aberrant synthesis, metabolism, and plasma accumulation of circulating estrogens and estrogen metabolites in preeclampsia implications for vascular dysfunction. Hypertension 61: 480-487, 2013.

10. Molvarec A, Vér A, Fekete A, Rosta K, Derzbach L, Derzsy Z, Karádi I and Rigó J Jr: Association between estrogen receptor alpha (ESR1) gene polymorphisms and severe preeclampsia. Hypertens Res 30: 205-211, 2007.

11. Maruyama A, Nakayama T, Sato N, Mizutani Y, Furuya K and Yamamoto T: Association study using single nucleotide polymorphisms in the estrogen receptor beta (ESR2) gene for preeclampsia. Hypertens Res 27: 903-909, 2004.

12. Thomas P, Pang Y, Filardo EJ and Dong J: Identity of an estrogen membrane receptor coupled to a $\mathrm{G}$ protein in human breast cancer cells. Endocrinology 146: 624-632, 2005.

13. Revankar CM, Cimino DF, Sklar LA, Arterburn JB and Prossnitz ER: A transmembrane intracellular estrogen receptor mediates rapid cell signaling. Science 307: 1625-1630, 2005.

14. Tong C, Feng X, Chen J, Qi X, Zhou L, Shi S, Kc K, Stanley JL, Baker PN and Zhang H: G protein-coupled receptor 30 regulates trophoblast invasion and its deficiency is associated with preeclampsia. J Hypertens 34: 710-718, 2016.

15. Li J, Chen Z, Zhou X, Shi S, Qi H, Baker PN and Zhang H: Imbalance between proliferation and apoptosis-related impaired GPR30 expression is involved in preeclampsia. Cell Tissue Res 366: 499-508, 2016.

16. Prossnitz ER, Arterburn JB and Sklar LA: GPR30: A $\mathrm{G}$ protein-coupled receptor for estrogen. Mol Cell Endocrinol 265-266: 138-142, 2007.

17. Hung TH, Skepper JN, Charnock-Jones DS and Burton GJ: Hypoxia-reoxygenation: A potent inducer of apoptotic changes in the human placenta and possible etiological factor in preeclampsia. Circ Res 90: 1274-1281, 2002.

18. Luo X, Yao ZW, Qi HB, Liu DD, Chen GQ, Huang S and Li QS: Gadd $45 \alpha$ as an upstream signaling molecule of p38 MAPK triggers oxidative stress-induced sFlt- 1 and sEng upregulation in preeclampsia. Cell Tissue Res 344: 551-565, 2011.

19. Dhar-Mascareño $M$, Cárcamo JM and Golde DW: Hypoxia-reoxygenation-induced mitochondrial damage and apoptosis in human endothelial cells are inhibited by vitamin C. Free Radic Biol Med 38: 1311-1322, 2005.

20. Lee SR and Lo EH: Interactions between p38 mitogen-activated protein kinase and caspase- 3 in cerebral endothelial cell death after hypoxia-reoxygenation. Stroke 34: 2704-2709, 2003. 
21. Lee SR and Lo EH: Induction of caspase-mediated cell death by matrix metalloproteinases in cerebral endothelial cells after hypoxia-reoxygenation. J Cereb Blood Flow Metab 24: 720-727, 2004.

22. Tian R, Wang Z, Shi Z, Li D, Wang Y, Zhu Y, Lin W, Gui Y and Zheng XL: Differential expression of G-protein-coupled estrogen receptor-30 in human myometrial and uterine leiomyoma smooth muscle. Fertil Steril 99: 256-263, 2013.

23. Otto C, Rohde-Schulz B, Schwarz G, Fuchs I, Klewer M, Brittain D, Langer G, Bader B, Prelle K, Nubbemeyer R, et al: $\mathrm{G}$ protein-coupled receptor 30 localizes to the endoplasmic reticulum and is not activated by estradiol. Endocrinology 149: 4846-4856, 2008

24. Yang Z, Bai B, Luo X, Xiao X, Liu X, Ding Y, Zhang H, Gao L, Li J and Qi H: Downregulated Krüppel-like factor 8 is involved in decreased trophoblast invasion under hypoxia-reoxygenation conditions. Reprod Sci 21: 72-81, 2014.

25. Marconcini L, Marchiò S, Morbidelli L, Cartocci E, Albini A, Ziche M, Bussolino F and Oliviero S: c-fos-induced growth factor/vascular endothelial growth factor D induces angiogenesis in vivo and in vitro. Proc Natl Acad Sci USA 96: 9671-9676, 1999.

26. Kim KM, Kim NS, Kim J, Park JS, Yi JM, Lee J and Bang OS: Magnolol suppresses vascular endothelial growth factor-induced angiogenesis by inhibiting Ras-dependent mitogen-activated protein kinase and phosphatidylinositol 3-kinase/Akt signaling pathways. Nutr Cancer 65: 1245-1253, 2013.

27. Batenburg WW, Jansen PM, van den Bogaerdt AJ and J Danser AH: Angiotensin II-aldosterone interaction in human coronary microarteries involves GPR30, EGFR, and endothelial NO synthase. Cardiovasc Res 94: 136-143, 2012.

28. Li ZL, Liu JC, Liu SB, Li XQ, Yi DH and Zhao MG: Improvement of vascular function by acute and chronic treatment with the GPR30 agonist G1 in experimental diabetes mellitus. PLoS One 7: e38787, 2012.

29. Redman CW and Sargent IL: Placental debris, oxidative stress and pre-eclampsia. Placenta 21: 597-602, 2000.
30. Allaire AD, Ballenger KA, Wells SR, McMahon MJ and Lessey BA: Placental apoptosis in preeclampsia. Obstet Gynecol 96: 271-276, 2000.

31. Burton GJ, Charnock-Jones DS and Jauniaux E: Regulation of vascular growth and function in the human placenta. Reproduction 138: 895-902, 2009.

32. Cong B, Xu Y, Sheng H, Zhu X, Wang L, Zhao W, Tang Z, Lu J and Ni X: Cardioprotection of $17 \beta$-estradiol against hypoxia/reoxygenation in cardiomyocytes is partly through up-regulation of CRH receptor type 2. Mol Cell Endocrinol 382: 17-25, 2014.

33. Murata T, Dietrich $\mathrm{HH}$, Xiang $\mathrm{C}$ and Dacey $\mathrm{RG} \mathrm{Jr}$ : $\mathrm{G}$ protein-coupled estrogen receptor agonist improves cerebral microvascular function after hypoxia/reoxygenation injury in male and female rats. Stroke 44: 779-785, 2013.

34. Granger DN, Kvietys PR and Perry MA: Leukocyte - endothelial cell adhesion induced by ischemia and reperfusion. Can J Physiol Pharmacol 71: 67-75, 1993.

35. Zulueta JJ, Sawhney R, Yu FS, Cote CC and Hassoun PM: Intracellular generation of reactive oxygen species in endothelial cells exposed to anoxia-reoxygenation. Am J Physiol 272: L897-L902, 1997.

36. Song Y, Zhao XP, Song K and Shang ZJ: Ephrin-A1 is up-regulated by hypoxia in cancer cells and promotes angiogenesis of HUVECs through a coordinated cross-talk with eNOS. PLoS One 8: e74464, 2013.

37. Rowlands DJ,Chapple S, Siow RC and Mann GE: Equol-stimulated mitochondrial reactive oxygen species activate endothelial nitric oxide synthase and redox signaling in endothelial cells: Roles for F-actin and GPR30. Hypertension 57: 833-840, 2011.

38. Kolkova Z, Casslén V, Henic E, Ahmadi S, Ehinger A, Jirström K and Casslén B: The G protein-coupled estrogen receptor 1 (GPER/GPR30) does not predict survival in patients with ovarian cancer. J Ovarian Res 5: 9, 2012. 